\title{
Detection of Multi Fuzzy Semipreclosed Sets in Topological Space
}

\author{
S. Vinoth, P. Uma Maheswari, K. Arjunan
}

\begin{abstract}
In this paper, we study some of the properties of interval valued intuitionistic multi fuzzy generalized semi preclosed sets. Also we have provided the relation between interval valued intuitionistic multi fuzzy generalized semipre closed sets with other interval valued intuitionistic multi fuzzy sets.
\end{abstract}

KEYWORDS: Fuzzy subset, interval valued intuitionistic multi fuzzy subset, interval valued intuitionistic multi fuzzy topological space, interval valued intuitionistic multi fuzzy interior, interval valued intuitionistic multi fuzzy closure.

\section{INTRODUCTION:}

In 1965, Zadeh [16] introduced the notion of a fuzzy subset of a set, fuzzy sets are a kind of useful mathematical structure to represent a collection of objects whose boundary is vague. Some interesting theorems and results on interval valued intuitionistic multi fuzzy generalized semipreclosed sets are provided in this paper.

\section{PRELIMINARIES:}

1.1 Definition[16]: Let $Z(\neq \varnothing)$ be a set. A fuzzy subset $F$ of $\mathrm{Z}$ is a function

$\mathrm{F}: \mathrm{Z} \rightarrow[0,1]$.

1.2 Definition[16]: A multi fuzzy subset $M$ of a set $Z$ is defined as an object of the form $M=\left\{\left\langle z, M_{1}(z), M_{2}(z)\right.\right.$, $\left.\left.M_{3}(z), \ldots, M_{n}(z)\right\rangle / z \in Z\right\}$, where $M_{i:} Z \rightarrow[0,1]$ for all i. It is denoted as $\mathrm{M}=\left\langle\mathrm{M}_{1}, \mathrm{M}_{2}, \mathrm{M}_{3}, \ldots, \mathrm{M}_{\mathrm{n}}\right\rangle$.

1.3 Definition[16]: Let $Z(\neq \varnothing)$ be a set. $A$ interval valued fuzzy subset $\mathrm{I}$ of $\mathrm{Z}$ is a function $\mathrm{I}: \mathrm{Z} \rightarrow \mathrm{D}[0,1]$, where $D[0,1]$ denotes the family of all closed subintervals of $[0$, 1].

1.4 Definition[16]: A interval valued multi fuzzy subset $A$ of a set $Z$ is defined as an object of the form $A=\left\{\left\langle z, A_{1}(z)\right.\right.$, $\left.\left.\mathrm{A}_{2}(\mathrm{z}), \mathrm{A}_{3}(\mathrm{z}), \ldots, \mathrm{A}_{\mathrm{n}}(\mathrm{z})\right\rangle / \mathrm{z} \in \mathrm{Z}\right\}$, where $\mathrm{A}_{\mathrm{i}}$ :

$\mathrm{Z} \rightarrow \mathrm{D}[0,1]$ for all $\mathrm{i}$, where $D[0,1]$ denotes the family of all closed subintervals of $[0,1]$. It is denoted as $A=\left\langle A_{1}, A_{2}\right.$, $\left.A_{3}, \ldots, A_{n}\right\rangle$.

1.5 Definition[1]: An intuitionistic fuzzy subset( IFS ) A of a set $Z$ is defined as an

object of the form $A=\{$ $\left.\left\langle\mathrm{z}, \quad \lambda_{\mathrm{A}}(\mathrm{z}), \quad \delta_{\mathrm{A}}(\mathrm{z})\right\rangle / \mathrm{z} \in \mathrm{Z}\right\}$, where $\lambda_{\mathrm{A}}: \mathrm{Z} \rightarrow[0,1]$ and $\delta_{\mathrm{A}}: Z \rightarrow[0,1]$ define the degree of membership and the degree of non-membership of the element $\mathrm{Z}$ in $\mathrm{Z}$ respectively and for every $\mathrm{z}$ in $\mathrm{Z}$ satisfying $0 \leq \lambda_{\mathrm{A}}(\mathrm{z})+$ $\delta_{\mathrm{A}}(\mathrm{z}) \leq 1$.

Revised Manuscript Received on December 15, 2019.

S.Vinoth, Assistant Professor, Division of Mathematics, VFSTR,Guntur- 522213, India , Email:vinomaths6@gmail.com

P.Uma Maheswari, Associate Professor, of Mathematics, Maamallan Institute of Technology, Sriperumbudur - 602 105, Tamilnadu. Email: mathuma_78@yahoo.co.in

K.Arjunan, Department of Mathematics, Alagappa Government Arts College, Karaikudi - 630003 , Tamilnadu, India.

Email: arjunan.karmegam@gmail.com
1.6 Example: Let $Z=\{a, b, c\}$ be a set. Then $A=\{\langle a$, $0.521,0.342\rangle$, $\langle\mathrm{b}, 0.145,0.713\rangle,\langle\mathrm{c}$, $0.256,0.341\rangle\}$ is an intuitionistic fuzzy subset of $\mathrm{Z}$.

1.7 Definition[1]: A intuitionistic multi fuzzy subset (IMFS) $\mathrm{A}$ of a set $\mathrm{Z}$ is defined as an object of the form $\mathrm{A}=$ $\left\{\left\langle\mathrm{z}, \lambda_{\mathrm{A}}(\mathrm{z}), \delta_{\mathrm{A}}(\mathrm{z})\right\rangle / \mathrm{z} \in \mathrm{Z}\right\}$, where $\lambda_{\mathrm{A}}(\mathrm{z})=\left(\lambda_{\mathrm{A} 1}(\mathrm{z}), \lambda_{\mathrm{A} 2}(\mathrm{z})\right.$, $\left.\ldots \lambda_{\mathrm{An}}(\mathrm{z})\right), \lambda_{\mathrm{Ai}}: \mathrm{Z} \rightarrow[0,1]$ for all $\mathrm{i}$ and $\delta_{\mathrm{A}}(\mathrm{z})=\left(\delta_{\mathrm{A} 1}(\mathrm{z})\right.$, $\left.\delta_{\mathrm{A} 2}(\mathrm{z}), \ldots, \delta_{\mathrm{An}}(\mathrm{z})\right), \quad \delta_{\mathrm{Ai}}: \mathrm{Z} \rightarrow[0,1]$ for all $\mathrm{i}$, define the degree of membership and the degree of nonmembership of the element $\mathrm{z}$ in $\mathrm{Z}$ respectively and for every $\mathrm{z}$ in $\mathrm{Z}$ satisfying $\quad 0 \leq \lambda_{\mathrm{Ai}}(\mathrm{z})+\delta_{\mathrm{Ai}}(\mathrm{z}) \leq 1$ for all $\mathrm{i}$.

1.8 Definition: A interval valued intuitionistic multi fuzzy subset (IVIMFS) $\mathrm{M}$ of a set $\mathrm{Z}$ is defined as an object of the form $\mathrm{M}=\left\{\left\langle\mathrm{z}, \lambda_{\mathrm{M}}(\mathrm{z}), \delta_{\mathrm{M}}(\mathrm{z})\right\rangle / \mathrm{z} \in \mathrm{Z}\right\}$, where $\lambda_{\mathrm{M}}(\mathrm{z})$ $=\left(\lambda_{\mathrm{M} 1}(\mathrm{z}), \lambda_{\mathrm{M} 2}(\mathrm{z}), \ldots \lambda_{\mathrm{Mn}}(\mathrm{z})\right), \lambda_{\mathrm{Mi}}: \mathrm{Z} \rightarrow \mathrm{D}[0,1]$ for all $\mathrm{i}$ and $\delta_{\mathrm{M}}(\mathrm{z})=\left(\delta_{\mathrm{M} 1}(\mathrm{z}), \delta_{\mathrm{M} 2}(\mathrm{z}), \ldots, \delta_{\mathrm{Mn}}(\mathrm{z})\right), \delta_{\mathrm{Mi}}: \mathrm{Z} \rightarrow \mathrm{D}[0,1]$ for all $i$, define the degree of membership and the degree of nonmembership of the element $\mathrm{z}$ in $\mathrm{Z}$ respectively and for every $\mathrm{z}$ in $\mathrm{Z}$ satisfying $0 \leq \sup \lambda_{\mathrm{Mi}}(\mathrm{z})+\sup \delta_{\mathrm{Mi}}(\mathrm{z}) \leq 1$ for all $\mathrm{i}$, where $D[0,1]$ denotes the family of all closed subintervals of $[0,1]$.

1.9 Definition: Let $M$ and $N$ be any two interval valued intuitionistic multi fuzzy subsets of a set $\mathrm{Z}$. We define the following relations and operations:

(i) $\mathrm{M} \subseteq \mathrm{N}$ iff $\lambda_{\mathrm{M}}(\mathrm{z}) \leq \lambda_{\mathrm{N}}(\mathrm{z})$ and $\delta_{\mathrm{M}}(\mathrm{z}) \geq \delta_{\mathrm{N}}(\mathrm{z})$, for all $\mathrm{z}$ in $\mathrm{Z}$.

(ii) $\mathrm{M}=\mathrm{N}$ iff $\lambda_{\mathrm{M}}(\mathrm{z})=\lambda_{\mathrm{N}}(\mathrm{z})$ and $\delta_{\mathrm{M}}(\mathrm{z})=\delta_{\mathrm{N}}(\mathrm{z})$, for all $\mathrm{z}$ in Z.

(iii) $\mathrm{M}^{\mathrm{c}}=\left\{\left\langle\mathrm{z}, \delta_{\mathrm{M}}(\mathrm{z}), \lambda_{\mathrm{M}}(\mathrm{z})\right\rangle / \mathrm{z} \in \mathrm{Z}\right\}$.

(iv) $\mathrm{M} \cap \mathrm{N}=\left\{\left\langle\mathrm{z}, \min \left\{\lambda_{\mathrm{M}}(\mathrm{z}), \lambda_{\mathrm{N}}(\mathrm{z})\right\}, \max \left\{\delta_{\mathrm{M}}(\mathrm{z}), \delta_{\mathrm{N}}(\mathrm{z})\right\}\right\rangle\right.$ / $\mathrm{z} \in \mathrm{Z}\}$.

(v) $\mathrm{M} \cup \mathrm{N}=\left\{\left\langle\mathrm{z}, \max \left\{\lambda_{\mathrm{M}}(\mathrm{z}), \lambda_{\mathrm{N}}(\mathrm{z})\right\}, \min \left\{\delta_{\mathrm{M}}(\mathrm{z}), \delta_{\mathrm{N}}(\mathrm{z})\right\}\right\rangle\right.$ / $\mathrm{z} \in \mathrm{Z}$ \}.

1.10 Definition: Let $Z$ be a set and $\mathfrak{I}$ be a family of interval valued intuitionistic multi fuzzy subsets of $Z$. The family $\mathfrak{I}$ is called an interval valued intuitionistic multi fuzzy topology(IVIMFT) on $\mathrm{Z}$ iff $\mathfrak{I}$ satisfies the following axioms (i) $0_{\mathrm{Z}}, 1_{\mathrm{Z}} \in \mathfrak{I}$,

(ii) If $\left\{\mathrm{M}_{\mathrm{i}} ; \mathrm{i} \in \mathrm{I}\right\} \subseteq \mathfrak{I}$, then $\underset{i \in I}{\cup} M_{i} \in \mathfrak{I}$,

(iii) If $\mathrm{M}_{1}, \mathrm{M}_{2}, \mathrm{M}_{3}, \ldots \ldots \mathrm{M}_{\mathrm{n}} \in \mathfrak{I}$, then $\bigcap_{i=1}^{i=n} M_{i} \in \mathfrak{I}$. The pair $(Z, \mathfrak{I})$ is called an interval valued intuitionistic multi fuzzy topological space (IVIMFTS). The members of $\mathfrak{I}$ are called interval valued intuitionistic multi fuzzy open sets(IVIMFOSs) in Z. An interval valued intuitionistic multi fuzzy set $M$ in $Z$ is said to be interval valued intuitionistic multi fuzzy closed set(IVIMFCS) in $\mathrm{Z}$ iff if $\mathrm{M}^{\mathrm{c}}$ is an interval valued intuitionistic multi fuzzy open set in $\mathrm{Z}$. 


\section{Detection of Multi Fuzzy Semipreclosed Sets in Topological Space}

1.11 Definition: Let ( $\mathrm{Z}, \mathfrak{I}$ ) be an IVIMFTS and $\mathrm{M}$ be an IVIMFS in $Z$. Then the interval valued intuitionistic multi fuzzy interior and interval valued intuitionistic multi fuzzy closure are defined by

$\operatorname{ivimfint}(\mathrm{M})=\mathrm{U}\{G: G$ is an IVIMFOS in $\mathrm{Z}$ and $\mathrm{G} \subseteq \mathrm{M}\}$ ivimfcl(M) $=\left\{\mathrm{K}^{*} K\right.$ is an IVIMFCS in $\mathrm{Z}$ and $\left.\mathrm{M} \subseteq K\right\}$.

For any IVIMFS A in $(Z, \mathfrak{I})$, we have

ivimfcl $\left(\mathrm{M}^{\mathrm{C}}\right)=(\text { ivimfint }(\mathrm{M}))^{\mathrm{C}}$ and ivimfint $\left(\mathrm{M}^{\mathrm{C}}\right)=$ $(\operatorname{ivimfcl}(\mathrm{M}))^{\mathrm{C}}$.

1.12 Definition: An IVIMFS $M$ of an IVIMFTS $(Z, \mathfrak{I})$ is said to be an

(i) interval valued intuitionistic multi fuzzy regular closed

$\begin{array}{lllllllllllllllll}\mathrm{s} & \mathrm{e} & \mathrm{t} & (\mathrm{I} & \mathrm{V} & \mathrm{I} & \mathrm{M} & \mathrm{F} & \mathrm{R} & \mathrm{C} & \mathrm{S}\end{array}$ $\mathrm{M}=\operatorname{ivimf} c l(\operatorname{ivimfint}(\mathrm{M}))$

(ii) interval valued intuitionistic multi fuzzy semiclosed set ( IVIMFSCS ) if

$i \operatorname{vimfint}(\operatorname{ivimfcl}(\mathrm{M})) \subseteq \mathrm{M}$

(iii) interval valued intuitionistic multi fuzzy preclosed set (

$\begin{array}{llllllllll}\text { I } & \text { V } & \text { I } & \text { M } & \text { F } & \text { P } & \text { C } & \text { S }) & \text { i } & \text { f }\end{array}$ ivimfcl(ivimfint $(\mathrm{M})) \subseteq \mathrm{M}$

(iv) interval valued intuitionistic multi fuzzy $\alpha$ closed set ( IVIMF $\alpha C S)$ if ivimfcl(ivimfint(ivimfcl $(\mathrm{M}))) \subseteq \mathrm{M}$

(v) interval valued intuitionistic multi fuzzy $\beta$ closed set ( IVIMF $\boldsymbol{\beta C S}$ ) if ivimfint $(\operatorname{ivimf} c l(\operatorname{ivimfint}(\mathrm{M}))) \subseteq \mathrm{M}$

1.13 Definition: An IVIMFS $M$ of an IVIMFTS $(Z, \mathfrak{I})$ is said to be an

(i) interval valued intuitionistic multi fuzzy generalized closed set ( IVIMFGCS) if

$\operatorname{ivimfcl}(\mathrm{M})=\mathrm{U}$ whenever $\mathrm{M} \subseteq U$ and $\mathrm{U}$ is an IVIMFOS

(ii) interval valued intuitionistic multi fuzzy regular generalized closed set

( IVIMFRGCS) if

$\operatorname{ivimf} c l(\mathrm{M}) \subseteq \mathrm{U}$, whenever $\mathrm{M} \subseteq U$ and $\mathrm{U}$ is an IVIMFROS.

1.14 Definition: An IVIMFS $M$ of an IVIMFTS $(Z, \mathfrak{I})$ is said to be an

(i) interval valued intuitionistic multi fuzzy semipreclosed set ( IVIMFSPCS) if there exists an IVIMFPCS $\mathrm{N}$ such that ivimfint $(\mathrm{N}) \subseteq \mathrm{M} \subseteq \mathrm{N}$.

(ii) interval valued intuitionistic multi fuzzy semipreopen set ( IVIMFSPOS) if there exists an IVIMFPOS $\mathrm{N}$ such that $\mathrm{N}$ $\subseteq \mathrm{M} \subseteq \operatorname{ivimfcl}(\mathrm{N})$

1.15 Definition: Let $A$ be an IVIMFS in an IVIMFTS (Z,

$\mathfrak{I})$. Then the interval valued intuitionistic multi fuzzy semipre interior of $\mathbf{M}$ (ivimfspint(M)) and the interval valued intuitionistic multi fuzzy semipre closure of $\mathrm{M}$ $(i \operatorname{vimfspcl}(\mathrm{M}))$ are defined by $i \operatorname{vimfspint}(\mathrm{M})=U\{G: G$ is an IVIMFSPOS in $\mathrm{Z}$ and $\mathrm{G} \subseteq \mathrm{M}\}$

ivimfspcl(M) $=\bigcap\{\mathrm{K}: K$ is an IVIMFSPCS in $\mathrm{Z}$ and $\mathrm{M}$ $\subseteq K\}$.

For any IVIMFS $\mathrm{M}$ in $(X, \mathfrak{\Im})$, we have ivimfspcl $\left(\mathrm{M}^{\mathrm{C}}\right)=$ $(i \operatorname{vimfspcl}(\mathrm{M}))^{\mathrm{C}}$ and ivimfspint $\left(\mathrm{M}^{\mathrm{C}}\right)=(\operatorname{ivimfspint}(\mathrm{M}))^{\mathrm{C}}$.

1.16 Definition: An IVIMFS $M$ in IVIMFTS $(Z, \mathfrak{I})$ is said to be an interval valued intuitionistic multi fuzzy generalized semipreclosed set ( IVIMFGSPCS) if ivimfspcl(M)) $\subseteq U$ whenever $\mathrm{M} \subseteq U$ and $\mathrm{U}$ is an IVIMFOS in $(\mathrm{Z}, \mathfrak{I})$.

1.17 Example: Let $X=\{a, b\}$ and $\mathrm{G}=\{\langle a,[0.5,0.5]$, $[0.55,0.55],[0.6,0.6]$, $[0.5,0.5],[0.45$, $0.45],[0.4,0.4]\rangle,\langle\mathrm{b},[0.4,0.4],[0.45,0.45],[0.5,0.5],[0.6$,
$0.6]$ $\left.\mathrm{G}, \mathrm{1}_{\mathrm{Z}}\right\}$ is an IVIMFTS on $\mathrm{Z}$.

Let $M=\{\langle a,[0.4,0.4],[0.45,0.45],[0.5,0.5],[0.6,0.6]$, $[0.55,0.55],[0.5,0.5]\rangle$,

$\langle\mathrm{b},[0.2,0.2]$, $[0.25,0.25],[0.3,0.3],[0.7,0.7],[0.65,0.65],[0.6,0.6]\rangle\}$ is an IVIMFGSPCS in $(\mathrm{Z}, \mathfrak{I})$.

\section{EXPERIMENTS AND RESULTS DESCRIPTION}

2.1 Theorem: Every IVIMFCS in $(Z, \mathfrak{I})$ is an IVIMFGSPCS in $(Z, \mathfrak{J})$.

Proof: Let A be an IVIMFCS in $(Z, \mathfrak{I})$. Assume that A $\subseteq U$ and $\mathrm{U}$ is an IVIMFOS in $(\mathrm{Z}, \mathfrak{I})$.Then ivimfspcl $(A) \subseteq \operatorname{ivimfcl}(A) \quad=A \subseteq U, \quad$ by hypothesis. Hence A is an IVIMFGSPCS in $(Z, \mathfrak{I})$.

2.2 Remark: The converse of above theorem is not necessary true

Proof: Consider the example, let $X=\{a, b\}$ and $\mathrm{G}=\{\langle$ a, [0.5, 0.5], [0.55, 0.55], [0.6, 0.6], [0.5, 0.5], [0.45, 0.45], $[0.4,0.4]\rangle,\langle\mathrm{b},[0.4,0.4],[0.45,0.45],[0.5,0.5],[0.6,0.6]$, $[0.55,0.55],[0.5,0.5]\rangle\}$. Then $\tau=\left\{0_{Z}, G, 1_{Z}\right\}$ is an IVIMFTS on Z. Let $\mathrm{A}=\{\langle\mathrm{a},[0.4,0.4],[0.45$, $0.45],[0.5,0.5],[0.6,0.6],[0.55,0.55],[0.5,0.5]\rangle$, $\langle\mathrm{b},[0.2,0.2],[0.25,0.25],[0.3,0.3],[0.7,0.7],[0.65,0.65]$, $[0.6,0.6]\rangle\}$ be an IVIMFS in $Z$. Then $A$ is an IVIMFGSPCS but not an IVIMFCS in Z.

2.3 Theorem: Every IVIMFRCS in $(Z, \mathfrak{I})$ is an IVIMFGSPCS in $(Z, \mathfrak{J})$.

Proof: Since every IVIMFRCS is an IVIMFCS, the proof is obvious from Theorem 2.1.

2.4 Remark: The converse of above theorem is not necessary true

Proof: Consider the example, let $X=\{a, b\}$ and $\mathrm{G}=\{\langle$ a, [0.4, 0.8], [0.45, 0.85], [0.5, 0.9], [0, 0], [0, 0], [0, 0] $\rangle,\langle\mathrm{b}$, $[0.3,0.6],[0.35,0.65],[0.4,0.7],[0,0],[0,0]$, $[0,0]\rangle\}$. Then $\tau=\left\{0_{Z}, G, 1_{Z}\right\}$ is an IVIMFTS on Z. Let $A$ $=\{\langle\mathrm{a},[0.3,0.6],[0.35,0.65],[0.4,0.7],[0,0],[0,0],[0,0]$ \rangle,$\langle\mathrm{b}, \quad[0.2,0.4], \quad[0.25,0.45], \quad[0.3,0.5], \quad[0,0]$, $[0,0],[0,0]\rangle\}$ be an IVIMFS in Z. Then $\mathrm{A}$ is an IVIMFGSPCS but not an IVIMFRCS in $\mathrm{Z}$.

2.5 Theorem: Every IVIMFGCS in $(X, \Im)$ is an IVIMFGSPCS in $(Z, \mathfrak{J})$.

Proof: Let A be an IVIMFGCS in $(Z, \mathfrak{I})$. Then assume that $A \subseteq U$ and $U$ is an IVIMFOS in $(Z, \mathfrak{I})$. Since ivimf $\operatorname{spcl}(A) \subseteq \operatorname{ivim} f c l(A)$ and

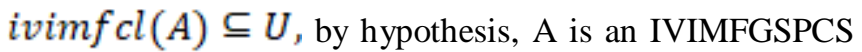
in $\mathrm{Z}$.

2.6 Remark: The converse of above theorem is not necessary true

Proof: Consider the example, let $X=\{a, b\}$ and $\mathrm{G}=\{\langle$ a, [0.5, 0.5], [0.55, 0.55], [0.6, 0.6], [0.5, 0.5], [0.45, 0.45], $[0.4,0.4]\rangle,\langle\mathrm{b},[0.4,0.4],[0.45,0.45],[0.5,0.5],[0.6,0.6]$, $[0.55,0.55],[0.5,0.5]\rangle\}$. Then $\tau=\left\{0_{\mathrm{Z}}, \mathrm{G}, 1_{\mathrm{Z}}\right\}$ is an IVIMFTS on Z. Let $\mathrm{A}=\{\langle\mathrm{a},[0.4,0.4],[0.45$, $0.45],[0.5,0.5],[06,0.6],[0.55,0.55],[0.5,0.5]\rangle$, $\langle\mathrm{b},[0.2,0.2],[0.25,0.25]$, $[0.3,0.3],[0.7,0.7],[0.65$, $0.65],[0.6,0.6]\rangle\}$ be an 
IVIMFS in $\mathrm{Z}$. Then $\mathrm{A}$ is an IVIMFGSPCS but not an IVIMFGCS in $\mathrm{Z}$.

2.7 Theorem: Every IVIMFSPCS in $(Z, \mathfrak{J})$ is an IVIMFGSPCS in $(Z, \mathfrak{I})$.

Proof: Let A be an IVIMFSPCS in Z. Assume that A $\subseteq U$ and $U$ is an IVIMFOS in $(Z, \mathfrak{I})$. Then since $\operatorname{ivimf} \operatorname{spcl}(A)=A, \quad$ we have ivimf $\operatorname{spcl}(A) \subseteq U$. Hence $\mathrm{A}$ is an IVIMFGSPCS in $(\mathrm{Z}, \mathfrak{I})$.

2.8 Remark: The converse of above theorem is not necessary true

Proof: Consider the example, let $X=\{a, b\}$ and $\mathrm{G}=\{<$ a, [0.5, 0.5], [0.55, 0.55], [0.6, 0.6], [0.5, 0.5], [0.45, 0.45], $[0.4,0.4]\rangle,\langle\mathrm{b},[0.6,0.6],[0.65,0.65],[0.7,0.7],[0.4,0.4]$, $[0.35,0.35],[0.3,0.3]\rangle\}$. Then $\tau=\left\{0_{Z}, G, 1_{Z}\right\}$ is an IVIMFTS on Z. Let $\mathrm{A}=\{\langle\mathrm{a},[0.5,0.5],[0.55$, $0.55],[0.6,0.6],[0.5,0.5],[0.45,0.45],[0.4,0.4]\rangle$, $\langle\mathrm{b},[0.7,0.7],[0.75,0.75],[0.8,0.8],[0.3,0.3],[0.25,0.25]$, $[0.2,0.2]\rangle\}$ be an IVIMFS in $\mathrm{Z}$. Then $\mathrm{A}$ is an IVIMFGSPCS but not an IVIMFSPCS in $\mathrm{Z}$.

2.9 Theorem: Every IVIMF $\alpha C S$ in $(Z, \mathfrak{I})$ is an IVIMFGSPCS in $(\mathrm{Z}, \mathfrak{I})$.

Proof: Since every IVIMF $\alpha$ CS is an IVIMFSPCS, the proof is obvious from Theorem 2.7.

2.10 Remark: The converse of above theorem is not necessary true

Proof: Consider the example, let $X=\{a, b\}$ and $\mathrm{G}=\{<$ a, [0.5, 0.5], [0.55, 0.55], [0.6, 0.6], [0.5, 0.5], [0.45, 0.45], $[0.4,0.4]\rangle,\langle\mathrm{b},[0.6,0.6],[0.65,0.65],[0.7,0.7],[0.4,0.4]$, $[0.35,0.35],[0.3,0.3]\rangle\}$. Then $\tau=\left\{0_{\mathrm{Z}}, \mathrm{G}, 1_{\mathrm{Z}}\right\}$ is an IVIMFTS on Z. Let $\mathrm{A}=\{\langle\mathrm{a},[0.5,0.5],[0.55$, $0.55],[0.6,0.6],[0.5,0.5],[0.45,0.45],[0.4,0.4]\rangle$, $\langle\mathrm{b},[0.7,0.7],[0.75,0.75],[0.8,0.8],[0.3,0.3],[0.25,0.25]$, $[0.2,0.2]\rangle\}$ be an IVIMFS in $\mathrm{Z}$. Then $\mathrm{A}$ is an IVIMFGSPCS but not an IVIMF $\alpha \mathrm{CS}$ in $(\mathrm{Z}, \mathfrak{I})$.

2.11 Theorem: Every IVIMF $\beta C S$ in $(Z, \mathfrak{I})$ is an IVIMFGSPCS in $(Z, \mathfrak{I})$.

Proof: Let $A$ be an IVIMF $\beta C S$ in $Z$. Assume that $A \subseteq U$, U is an IVIMFOS in $(\mathrm{Z}, \mathfrak{I})$.

Since $\operatorname{ivim} f \beta c l(A)=A$, we have $\operatorname{ivim} f \beta c l(A) \subseteq U$. Hence $\mathrm{A}$ is an IVIMFGSPCS in $(\mathrm{Z}, \mathfrak{I})$.

2.12 Remark: The converse of above theorem is not necessary true

Proof: Consider the example, let $X=\{a, b\}$ and $\mathrm{G}=\{\langle$ a, [0.5, 0.5], [0.55, 0.55], [0.6, 0.6], [0.5, 0.5], [0.45, 0.45], $[0.4,0.4]\rangle,\langle\mathrm{b},[0.6,0.6],[0.65,0.65],[0.7,0.7],[0.4,0.4]$, $[0.35,0.35],[0.3,0.3]\rangle\}$. Then $\tau=\left\{0_{\mathrm{Z}}, \mathrm{G}, 1_{\mathrm{Z}}\right\}$ is an IVIMFTS on Z. Let $\mathrm{A}=\{\langle\mathrm{a},[0.5,0.5],[0.55$, 0.55], [0.6, 0.6], [0.5, 0.5], [0.45, 0.45], [0.4, 0.4] $\rangle$,

$\langle\mathrm{b},[0.7,0.7],[0.75,0.75],[0.8,0.8],[0.3,0.3],[0.25,0.25]$, $[0.2,0.2]\rangle\}$ be an IVIMFS in Z. Then $\mathrm{A}$ is an

IVIMFGSPCS but not an IVIMF $\beta C S$ in $\mathrm{Z}$.

2.13 Theorem: Every IVIMFSCS in $(Z, \mathfrak{I})$ is an IVIMFGSPCS in $(\mathrm{Z}, \mathfrak{J})$.

Proof: Let A be an IVIMFSCS in $(Z, \mathfrak{I})$. Since every IVIMFSCS is an IVIMFSPCS and by theorem 2.7, we have $\mathrm{A}$ is an IVIMFGSPCS in $(\mathrm{Z}, \mathfrak{I})$.

2.14 Remark: The converse of above theorem is not necessary true
Proof: Consider the example, let $X=\{a, b\}$ and $\mathrm{G}=\{\langle$ a, [0.5, 0.5], [0.55, 0.55], [0.6, 0.6], [0.5, 0.5], [0.45, 0.45], $[0.4,0.4]\rangle,\langle\mathrm{b},[0.6,0.6],[0.65,0.65],[0.7,0.7],[0.4,0.4]$, $[0.35,0.35],[0.3,0.3]\rangle\}$. Then $\tau=\left\{0_{\mathrm{Z}}, \mathrm{G}, 1_{\mathrm{Z}}\right\}$ is an IVIMFTS on Z. Let $\mathrm{A}=\{\langle\mathrm{a},[0.5,0.5],[0.55$, $0.55],[0.6,0.6],[0.5,0.5],[0.45,0.45],[0.4,0.4]\rangle$, $\langle\mathrm{b},[0.7,0.7],[0.75,0.75],[0.8,0.8],[0.3,0.3],[0.25,0.25]$, $[0.2,0.2]\rangle\}$ be an IVIMFS in $\mathrm{Z}$. Then $\mathrm{A}$ is an IVIMFGSPCS but not an IVIMFSCS in Z.

2.15 Theorem: Every IVIMFPCS in $(Z, \mathfrak{J})$ is an

IVIMFGSPCS in $(\mathrm{Z}, \mathfrak{I})$.

Proof: Since every IVIMFPCS is an IVIMFSPCS, the proof is obvious from Theorem 2.7 .

2.16 Remark: The converse of above theorem is not necessary true

Proof: Consider the example, let $X=\{a, b\}$ and $\mathrm{G}=\{\langle$ a, [0.5, 0.5], [0.55, 0.55], [0.6, 0.6], [0.5, 0.5], [0.45, 0.45], $[0.4,0.4]\rangle,\langle\mathrm{b},[0.6,0.6],[0.65,0.65],[0.7,0.7],[0.4,0.4]$, $[0.35,0.35],[0.3,0.3]\rangle\}$. Then $\tau=\left\{0_{Z}, G, 1_{Z}\right\}$ is an IVIMFTS on Z. Let $\mathrm{A}=\{\langle\mathrm{a},[0.5,0.5],[0.55$, $0.55],[0.6,0.6],[0.5,0.5],[0.45,0.45],[0.4,0.4]\rangle$, $\langle\mathrm{b},[0.7,0.7],[0.75,0.75],[0.8,0.8],[0.3,0.3],[0.25,0.25]$, $[0.2,0.2]\rangle\}$ be an IVIMFS in $\mathrm{Z}$. Then $\mathrm{A}$ is an IVIMFGSPCS but not an IVIMFPCS in Z.

2.17 Remark: The union of any two IVIMFGSPCS in $(Z, \mathfrak{I})$ is not an IVIMFGSPCS in $(Z, \mathfrak{I})$.

Proof: Consider the example, let $X=\{a, b\}$ and $\mathrm{A}_{1}=\{\langle$ a, [0.7, 0.7], [0.75, 0.75], [0.8, 0.8], [0.3, 0.3], [0.25, 0.25], $[0.2,0.2]\rangle,\langle\mathrm{b},[0.8,0.8],[0.85,0.85],[0.9,0.9],[0.2,0.2]$, $[0.15,0.15],[0.1,0.1]\rangle\}$ and

$\mathrm{A}_{2}=\{\langle\mathrm{a},[0.6,0.6],[0.65,0.65],[0.7,0.7],[0.4,0.4]$, $[0.35,0.35],[0.3,0.3]\rangle,\langle\mathrm{b},[0.7,0.7],[0.75,0.75],[0.8$, $0.8],[0.3,0.3],[0.25,0.25],[0.2,0.2]\rangle\}$. Then $\tau=\left\{0_{\mathrm{Z}}, \mathrm{A}_{1}\right.$, $\left.\mathrm{A}_{2}, 1_{\mathrm{Z}}\right\}$ is an IVIMFTS on Z. Let $\mathrm{A}=\{$ $\langle\mathrm{a},[0.6,0.6],[0.65,0.65],[0.7,0.7],[0.4,0.4],[0.35,0.35]$, $[0.3,0.3]\rangle$,

$\langle\mathrm{b},[0.4,0.4],[0.45$, $0.45],[0.5,0.5],[0.3,0.3],[0.25,0.25],[0.2,0.2]\rangle\}$ and $\mathrm{B}=\{\langle\mathrm{a},[0.4,0.4],[0.45,0.45],[0.5,0.5],[0.4,0.4],[0.35$, $0.35],[0.3,0.3]\rangle$, $\langle\mathrm{b},[0.8,0.8]$ $[0.85,0.85],[0.9,0.9],[0.2,0.2],[0.15,0.15],[0.1,0.1]\rangle\}$ be two IVIMFSs in Z. Then A and B are IVIMFGSPCS but $\mathrm{A} \cup B$ is not an IVIMFGSPCS in $\mathrm{Z}$, since $\mathrm{AU} B=\{\langle\mathrm{a}$, $[0.6,0.6],[0.65,0.65],[0.7,0.7],[0.4,0.4],[0.35,0.35]$, $[0.3,0.3]\rangle,\langle\mathrm{b},[0.8,0.8],[0.85,0.85],[0.9,0.9],[0.2,0.2]$, $[0.15,0.15],[0.1,0.1]\rangle\} \subseteq \mathrm{A}_{1}$ but ivimf $\operatorname{spcl}(A \cup B)=$ $1_{\mathrm{Z}} \notin \mathrm{A}_{1}$.

2.18 Remark: The intersection of two IVIMFGSPCS in $(Z, \mathfrak{I})$ is not an IVIMFGSPCS in $(Z, \mathfrak{I})$.

Proof: Consider the example, let $X=\{a, b\}$ and $\mathrm{G}=\{\langle$ a, [0.5, 0.5], [0.55, 0.55], [0.6, 0.6], [0.5, 0.5], [0.45, 0.45], $[0.4,0.4]\rangle,\langle\mathrm{b},[0.6,0.6],[0.65,0.65],[0.7,0.7],[0.4,0.4]$, $[0.35,0.35],[0.3,0.3]\rangle\}$. Then $\tau=\left\{0_{\mathrm{Z}}, \mathrm{G}, 1_{\mathrm{Z}}\right\}$ is an IVIMFTS on Z. Let $\mathrm{A}=\{\langle\mathrm{a},[0.5,0.5],[0.55$, $0.55],[0.6,0.6],[0.5,0.5],[0.45,0.45],[0.4,0.4]\rangle$, $\langle\mathrm{b},[0.7,0.7],[0.75,0.75],[0.8,0.8],[0.3,0.3],[0.25,0.25]$, $[0.2,0.2]\rangle\}$ and $\quad \mathrm{B}=\{\langle\mathrm{a},[0.6,0.6]$, 


\section{Detection of Multi Fuzzy Semipreclosed Sets in Topological Space}

$[0.65,0.65],[0.7,0.7],[0.4,0.4],[0.35,0.35],[0.3,0.3]\rangle$, $\langle\mathrm{b},[0.6,0.6],[0.65,0.65],[0.7,0.7],[0.4,0.4],[0.35,0.35]$, $[0.3,0.3]\rangle\}$ be IVIMFSs in $\mathrm{Z}$. Then $\mathrm{A}$ and $\mathrm{B}$ are IVIMFGSPCS but $A \cap B$ is not an IVIMFGSPCS in $\mathrm{Z}$, since $\mathrm{A} \cap \mathrm{B}=\{\langle\mathrm{a},[0.5,0.5],[0.55,0.55],[0.6,0.6],[0.5,0.5]$, $[0.45,0.45],[0.4,0.4]\rangle$, $\langle\mathrm{b},[0.6,0.6],[0.65$, $0.65],[0.7,0.7],[0.4,0.4],[0.35,0.35],[0.3,0.3]\rangle\} \subseteq \mathrm{G}$ but $\quad$ ivimf $\operatorname{spcl}(A \cap B)=1_{\mathrm{Z}} \not \mathrm{G}$.

2.19 Theorem: Let $(Z, \mathfrak{I})$ be an IVIMFTS. Then for every AE IVIMFGSPC(Z) and for every BEIVIMFS(Z), A $\subseteq B \subseteq$ ivimf $\operatorname{spcl}(A)$ implies BE IVIMFGSPC(Z).

Proof: Let $\mathrm{B} \subseteq U$ and $\mathrm{U}$ be an IVIMFOS in $(\mathrm{Z}, \mathfrak{I})$. Then since $\quad \mathrm{A} \subseteq B, A \subseteq U . \quad$ By hypothesis, $B \subseteq \operatorname{ivimf} \operatorname{spcl}(A)$.

Therefore ivimf $\operatorname{spcl}(B) \subseteq \operatorname{ivimf} \operatorname{spcl}(\operatorname{ivimf} \operatorname{spcl}(A))=\operatorname{ivim} f$ , since $\mathrm{A}$ is an IVIMFGSPCS in $(\mathrm{Z}, \mathfrak{I})$. Hence $\mathrm{B} \in \operatorname{IVIMFGSPC}(\mathrm{Z})$.

2.20 Theorem: Let $(X, \xi)$ be an IVIMFTS. Then every IVIMFS in $(X, \mathfrak{S})$ is an IVIMFGSPCS in $(X, \mathfrak{S})$ if and only if $\operatorname{IVIMFSPO}(Z)=\operatorname{IVIMFSPC}(Z)$.

Proof: Necessity: Suppose that every IVIMFS in $(X, \Im)$ is an IVIMFGSPCS in $(X, \Im)$. Let UE IVIMFO $(X)$. Then $\mathrm{UEIVIMFSPO}(X)$ and by hypothesis, ivimf $\operatorname{spcl}(U) \subseteq U \subseteq \operatorname{ivimf} \operatorname{spcl}(U) . \quad$ This implies ivimf $\operatorname{spcl}(U)=U$.

Therefore $\mathrm{UE} I V I M F S P C(X)$. $I V I M F S P O(X) \subseteq I V I M F S P C(X)$. Hence $\mathrm{A} \in I V I M F S P C(X)$. Let $\mathrm{A}^{\mathrm{C}} \in I V I M F S P O(X) \subseteq I V I M F S P C(X)$. That is $\mathrm{A}^{\mathrm{C}} \in I V I M F S P C(X)$. Therefore AEIVIMFSPO $(X)$. Hence IVIMFSPC $(X) \subseteq I V I M F S P O(X)$. Thus $\operatorname{IVIMFSPO}(X)=I V I M F S P C(X)$.

Sufficiency: Suppose that $\operatorname{IVIMFSPO}(X)=I V I M F S P C(X)$. Let $\mathrm{A} \subseteq U$ and $\mathrm{U}$ be an IVIMFOS in $(X, \Im)$. Then UE IVIMFSPO $(X)$ and $\operatorname{ivimf} \operatorname{spcl}(A) \subseteq \operatorname{ivimfspcl}(U)=U, \quad$ since UE IVIMFSPC $(Z)$, by hypothesis. Therefore $A$ is an IVIMFGSPCS in $\mathrm{Z}$.

2.21 Theorem: If $A$ is an IVIMFOS and an IVIMFGSPCS in $(X, \Im)$, then $\mathrm{A}$ is an IVIMFSPCS in $(X, \Im)$.

Proof: Since $\mathrm{A} \subseteq A$ and $\mathrm{A}$ is an IVIMFOS in $(X, \Im)$, by hypothesis, ivimf $\operatorname{spcl}(A) \subseteq A$. But $A \subseteq \operatorname{ivimf} \operatorname{spcl}(A)$.

Therefore $\operatorname{ivimf} \operatorname{spcl}(A)=A$. Hence $A$ is an IVIMFSPCS in $(X, \sqrt{5})$.

\section{REFERENCES}

1. Funes, José Félix, et al. "Defect detection from multi-frequency limited data via topological sensitivity." Journal of Mathematical Imaging and Vision 55.1 (2016): 19-35.

2. Glegrave, Romain Lucas, Dieter Pelz, and Rudy Palm. "The efficiency of the linear classification rule in multi-group discriminant analysis." African Journal of Mathematics and Computer Science Research 3.1 (2010): 019-025.

3. Benz, Ursula C., et al. "Multi-resolution, object-oriented fuzzy analysis of remote sensing data for GIS-ready information." ISPRS
Journal of photogrammetry and remote sensing 58.3-4 (2004): 239258 .

4. Westerman, Wayne. Hand tracking, finger identification, and chordic manipulation on a multi-touch surface. Diss. University of Delaware, 1999.

5. D'Orazio, Tiziana, and Cataldo Guaragnella. "A survey of automatic event detection in multi-camera third generation surveillance systems." International Journal of Pattern Recognition and Artificial Intelligence 29.01 (2015): 1555001.

6. Toosi, Adel Nadjaran, and Mohsen Kahani. "A new approach to intrusion detection based on an evolutionary soft computing model using neuro-fuzzy classifiers." Computer communications 30.10 (2007): 2201-2212.

7. Li, Zhixiong, et al. "Blind vibration component separation and nonlinear feature extraction applied to the nonstationary vibration signals for the gearbox multi-fault diagnosis." Measurement 46.1 (2013): 259-271.

8. Longbotham, Nathan, et al. "Multi-modal change detection, application to the detection of flooded areas: Outcome of the 20092010 data fusion contest." IEEE Journal of selected topics in applied earth observations and remote sensing 5.1 (2012): 331-342.

f Lemos, Andre, Walmir Caminhas, and Fernando Gomide. "Adaptive panfe (detection and diagnosis using an evolving fuzzy classifier." Information Sciences 220 (2013): 64-85

10. Markou, Markos, and Sameer Singh. "Novelty detection: a reviewpart 2:: neural network based approaches." Signal processing 83.12 (2003): 2499-2521. 